\title{
Pengaruh Kinerja Tutor Terhadap Kemandirian Belajar Mahasiswa dalam Problem Based Learning di Fakultas Kedokteran UISU
}

\author{
Martinus*, Gandes Retno Rahayu**, Ova Emilia** \\ * $\quad$ Fakultas Kedokteran Universitas Islam Sumatera Utara, Medan \\ ** Fakultas Kedokteran Universitas Gadjah Mada, Yogyakarta
}

\begin{abstract}
Background: For two years implementation of PBL in Faculty of Medicine Islamic University of Sumatera Utara several phenomenon should be evaluated such as various performance of tutor in facilitating PBL and student's self study not much. This research aimed to evaluate the relationship between tutor performance and student's self study and reporting process in $P B L$.

Method: This was observational analytical research, cross sectional study with population of all students of Faculty of Medicine Islamic University of Sumatera Utara. Primary data was collected from June to August 2009. Instrument used were tutor performance evaluation questionnaire, self learning activity evaluation questionnaire and student's self study and reporting process in PBL questionnaire with Likert scale. Kruskall Wallis test was used to assess the relationship between tutor and student performance.

Results: Average score of tutor performance on first year was higher compared to the second year students $(p=00,32)$. There is significant difference in student's self study and report process in PBL between high and moderate tutor performance's group $(p=0,000 ; p=0,000)$, high and low tutorperformance's group $(p=0.007, p=0,008)$, but not significant difference between moderate and low tutor performance's group $(p=0,111,0,280)$.

Conclusion: Tutor performance is related to higher level of student's self study and report process in PBL.
\end{abstract}

Keywords: PBL, tutor performance, self study, report process

\begin{abstract}
Abstrak
Latar Belakang: Selama 2 tahun menerapkan $P B L$ di FK - UISU, muncul beberapa fenomena yang perlu dicermati lebih lanjut, yaitu masih bervariasinya kinerja tutor dalam memfasilitasi PBL dan mahasiswa masih jarang belajar mandiri. Tujuan penelitian ini adalah untuk melakukan evaluasi hubungan kinerja tutor terhadap kegiatan belajar mandiri dan kegiatan pelaporan hasil belajar mandiri dalam $P B L$.

Metode: Penelitian observasional analitik, studi potong lintang, dengan populasi seluruh mahasiswa FK - UISU. Pengumpulan data primer dilakukan pada bulan Juni sampai Agustus 2009. Instrumen yang digunakan adalah kuesioner penilaian kinerja tutor dan kuesioner penilaian kegiatan belajar mandiri dan pelaporan hasil belajar mandiri mahasiswa, pengisian kuesioner dengan menggunakan skala Likert. Uji Kruskal Wallis untuk menilai hubungan kinerja tutor dan kinerja mahasiswa.

Hasil: Skor rata-rata kinerja tutor pada mahasiswa semester 2 lebih tinggi dibanding semester $4(p=0,032)$. Dan terdapat perbedaan kegiatan belajar mandiri dan pelaporan hasil belajar mandiri mahasiswa yang siginifikan pada kelompok kinerja tutor tinggi dengan kinerja tutor sedang $(p=0,000 ; p=0,000)$, kelompok kinerja tutor tinggi dengan kinerja tutor rendah $(\mathrm{p}=0,007 ; \mathrm{p}=0,008)$ tetapi antara kelompok tutor kinerja sedang dan kinerja tutor rendah tidak berbeda signifikan $(\mathrm{p}=0,111 ; 0,280)$.

Kesimpulan: Kinerja tutor yang baik berhubungan dengan kegiatan belajar mandiri dan pelaporan hasil belajar mandiri mahasiswa yang semakin tinggi.
\end{abstract}

Kata Kunci: PBL, kinerja tutor, belajar mandiri, pelaporan hasil belajar mandiri

Korespondensi: raifahmad@ymail.com 


\section{LATAR BELAKANG}

Penerapan Kurikulum Berbasis Kompetensi di FKUISU, mulai dilakukan sejak tahun 2007. Proses pendidikannya mengalami perubahan, banyak mata kuliah mulai diintegrasikan dalam blok belajar. Setiap minggu, tutorial dilakukan dalam 2 pertemuan @ 2 jam dalam 1 ruangan diikuti 10-12 mahasiswa yang dibimbing oleh seorang tutor, mahasiswa bertugas merumuskan tujuan belajar dari suatu masalah yang dibahas mengikuti 7 langkah (Seven Jumps In PBL).

Russel et al. seperti dikutip oleh Hendry et al. ${ }^{1}$ mengemukakan bahwa penerapan Problem Based Learning (PBL) didasarkan pada pendekatan yang konsisten pada proses belajar-mengajar yang konstruktivis. Van Berkel dan Dolmans ${ }^{2}$ juga mengemukakan bahwa karakteristik PBL sebagai suatu pendekatan belajar yang konstruktivis, adalah memacu mahasiswa sebagai pembelajar yang aktif, belajar secara mandiri, kontekstual dan kolaboratif; sehingga proses belajar mandiri mahasiswa yang dilakukan secara aktif dalam membentuk pengetahuan baru merupakan suatu komponen kunci dalam paham konstruktivisme.

Gijselaers dan Schmidt seperti disitasi oleh Hendry et al. ${ }^{1}$ juga telah mengajukan model teoritis $P B L$ yang menggambarkan hubungan faktor-faktor terkait PBL, yaitu variabel masukan (prior knowledge, tutor performance) akan mempengaruhi variabel proses (group functioning, time spent in individual study) sehingga akhirnya juga mempengaruhi variabel luaran (achievement, interest in subject matter). Walaupun demikian, bagaimana variabel ini saling mempengaruhi satu sama lain, masih belum dapat dijelaskan secara tepat. ${ }^{1}$

Pada fase belajar mandiri (langkah 6 tutorial), mahasiswa akan mencari informasi tambahan yang relevan dari berbagai macam sumber pengetahuan yang ada. Keluasan dan keberagaman informasi yang diperoleh mahasiswa pada saat belajar mandiri, akan menentukan pemahaman mahasiswa terhadap tujuan belajar yang dicapai. Hal ini dapat dilihat dari kedalaman dan keluasan diskusi yang dilakukan mahasiswa selama fase pelaporan (langkah 7 tutorial)., ${ }^{3,4}$ Musal et al. juga melaporkan temuannya bahwa semakin pengalaman mahasiswa dalam belajar PBL maka mereka akan menjadi pembelajar yang semakin mandiri. ${ }^{5}$
Sejak implementasi PBLdi FKUISU, penulis mengamati beberapa fenomena yang terjadi diantaranya masih bervariasinya kinerja tutor dalam memfasilitasi PBL dan mahasiswa juga terlihat masih jarang belajar mandiri, baik pada mahasiswa semester 2 ataupun mahasiswa semester 4 Fakultas Kedokteran UISU.

Penelitian ini bertujuan mengetahui pengaruh kinerja tutor terhadap kegiatan belajar mandiri dan kegiatan pelaporan hasil belajar mandiri mahasiswa dalam PBL.

\section{METODE}

Penelitian ini merupakan penelitian potong lintang dengan pendekatan kuantitatif analitik observasional. Populasi penelitian ini adalah seluruh mahasiswa KBK FK UISU, dengan kriteria inklusi:

1. Terdaftar sebagai mahasiswa aktif FK UISU

2. Ikut dalam seluruh kegiatan tutorial dalam 1 minggu (minggu ke-6) blok yang sedang berlangsung

Penelitian ini meneliti 3 variabel, yaitu variabel bebas: kinerja tutor dalam memfasilitasi $P B L$, variabel terikat adalah kegiatan belajar mandiri dan pelaporan hasil belajar mandiri mahasiswa dalam PBL.

Kinerja tutor didefinisikan sebagai kemampuan tutor dalam memfasilitasi proses diskusi tutorial pertama sampai pada perumusan tujuan belajar (learning issues) mahasiswa, yang terbatas pada kemampuan dalam merangsang belajar aktif/ konstruktif dan mandiri mahasiswa, memfasilitasi mahasiswa belajar secara kontekstual dan kolaboratif serta mampu berperilaku interpersonal dengan baik. Variabel diukur menggunakan kuesioner yang diadaptasi dan diterjemahkan langsung dari "Short Tutor Evaluation Questionnaire, Maastricht Medical School (2002-2003)" skala Likert dengan jawaban sangat tidak setuju (skala 1) sampai jawaban sangat setuju (skala 5). Dalam melakukan interpretasi kinerja tutor, maka skor total kuesioner penilaian kinerja tutor diklasifikasikan menjadi 3 tingkatan, yaitu: kinerja tutor rendah (skor $<25,67)$; kinerja tutor sedang $(25,67 \mathrm{~d}$ " Skor $<40,33)$; dan kinerja tutor tinggi (skor e" 40,33).

Untuk mengukur kegiatan belajar mandiridan pelaporan hasil belajar mandiri mahasiswa digunakan kuesioner 
yang diadaptasi dan diterjemahkan langsung dari "Self study and Reporting Process Questionnaire, Maastricht Medical School"', menggunakan skala Likert dengan jawaban sangat tidak setuju (skala 1) sampai jawaban sangat setuju (skala 5). Dalam melakukan interpretasi dan evaluasi variabel belajar mandiri dan pelaporan hasil belajar mandiri mahasiswa ini, maka skor total yang diperoleh akan dikonversi menjadi skala 1 (minimal) sampai skala 5 (maksimal).

Sebelum dilakukan pengumpulan data primer, seluruh instrumen yang akan digunakan telah diuji kesahihan dan kehandalannya. Setelah itu, pertanyaan dalam kuesioner diperbaiki, dan dilanjutkan dengan pengambilan data penelitian.

Pengambilan data primer dilakukan pada mahasiswa semester kedua blok VI (Sistem Muskuloskeletal) dan mahasiswa semester keempat blok XII (Sistem Reproduksi). Seluruh populasi penelitian diberi penjelasan tentang penelitian yang dilakukan untuk memperoleh persetujuan dan bersedia menjadi responden dalam penelitian ini. Kuesioner pertama penilaian kinerja tutor diisi oleh mahasiswa pada akhir tutorial I pada minggu ke-6 blok dan pada akhir tutorial II pada minggu yang sama, kuesioner kedua dibagikan untuk diisi responden.
Data penelitian yang terkumpul sebanyak 425 responden dari 480 mahasiswa (response rate 85,54\%). Dari 425 responden yang mengembalikan kuesioner, ada 39 mahasiswa yang mengundurkan diri saat penelitian dan 18 responden yang tidak mengisi kuesioner dengan lengkap, jadi keseluruhan data penelitian yang dapat dianalisis adalah 368 responden. Seluruh data yang terkumpul diolah dan dianalisis dengan menggunakan bantuan program SPSS versi 16.

Dari data peneiitian yang diperoleh dilakukan analisis kesahihan, keterandalan kuesioner, dan uji normalitas. Uji Kruskal Wallis untuk melihat perbedaan hubungan kinerja tutor terhadap kegiatan belajar mandiri mahasiswa dan kegiatan pelaporan hasil belajar mandiri mahasiswa.

\section{HASIL}

\section{Karakteristik responden}

Pada Tabel 1 dapat dilihat data yang terkumpul, terdiri dari 216 mahasiswa semester 2 (response rate 8,5\%) dan 152 mahasiswa semester 4 (response rate $88,57 \%$ ).

Tabel 1. Karakteristik responden berdasarkan jenis kelamin

\begin{tabular}{ccccc} 
& \multicolumn{2}{c}{ Semester 2 } & \multicolumn{2}{c}{ Semester 4} \\
\cline { 2 - 5 } & $\mathbf{N}$ & $\%$ & $\mathbf{N}$ & $\%$ \\
\hline Laki-laki & 59 & 27,3 & 50 & 32,9 \\
\hline Perempuan & 157 & 72,7 & 102 & 67,1 \\
\hline Total & 216 & 100 & 152 & 100 \\
\hline
\end{tabular}

Skor rata-rata kinerja tutor, kegiatan belajar mandiri dan pelaporan hasil belajar mandiri pada mahasiswa semester 2 dan semester 4

Pada Tabel 2 dapat dilihat skor rata-rata kinerja tutor pada mahasiswa semester 2 dan semester 4 menunjukkan kinerja tinggi. Skor rata-rata kinerja tutor pada mahasiswa semester 2 lebih tinggi daripada skor kinerja tutor pada mahasiswa semester 4 (Mann-Whitney $U=14,267,5 ; \mathrm{p}=$
0,032). Pada variabel kegiatan belajar mandiri, skor ratarata kegiatan belajar mandiri dan pelaporan hasil belajar mandiri pada mahasiswa semester 2 dan mahasiswa semester 4 cukup baik. Dan skor rata-rata kegiatan belajar mandiri mahasiswa semester 2 sedikit lebih baik daripada mahasiswa semester $4(p<0.05)$. Tetapi pada skor ratarata kegiatan pelaporan hasil belajar mandiri mahasiswa kedua kelompok tidak berbeda secara signifikan $(p>0,05)$. 
Tabel 2. Nilai skor rata-rata kinerja tutor, kegiatan belajar mandiri dan pelaporan hasil belajar mandiri pada mahasiswa semester 2 dan semester 4

\begin{tabular}{|c|c|c|c|c|c|c|c|}
\hline \multirow{2}{*}{ Variabel } & \multicolumn{2}{|c|}{ Mean \pm SD } & \multicolumn{2}{|c|}{ Skor Terendah } & \multicolumn{2}{|c|}{ Skor Tertinggi } & \multirow{2}{*}{$\begin{array}{l}\text { Uji Mann- } \\
\text { Whitney U }\end{array}$} \\
\hline & Semester & Semester & Semester 2 & Semester 4 & Semester 2 & Semester 4 & \\
\hline $\begin{array}{l}\text { Kinerja } \\
\text { Tutor }\end{array}$ & $41,88 \pm 7,37$ & $40,88 \pm 5,57$ & 13 & 17 & 55 & 51 & $\mathrm{p}^{-0,0.32^{*}}$ \\
\hline $\begin{array}{c}\text { Kegiatan } \\
\text { Belajar Mandiri }\end{array}$ & $3,73 \pm 0,47$ & $3,64 \pm 0,44$ & 1,43 & 2,50 & 5 & 5 & $p=0,009^{*}$ \\
\hline $\begin{array}{c}\text { Kegiatan Pelaporan } \\
\text { Hasil Belajar } \\
\text { Mandiri }\end{array}$ & $3,66 \pm 0,50$ & $3,63 \pm 0,50$ & 1,25 & 1,50 & 5 & 5 & $\mathrm{p}=0,550$ \\
\hline
\end{tabular}

Perbedaan skor rata-rata kegiatan belajar mandiri dan kegiatan pelaporan hasil belajar mandiri mahasiswa berdasarkan kategori kinerja tutor

Pada Tabel 3 dapat dilihat hubungan antara kegiatan belajar mandiri mahasiswa dengan kegiatan pelaporan hasil belajar mandiri mahasiswa berdasarkan kategori kinerja tutor. Dengan hasil uji statistik Kruskal Wallis yang bermakna, berarti setidaknya ada 2 kelompok kategori kinerja tutor yang memiliki skor rata-rata kegiatan belajar mandiri dan pada kegiatan pelaporan hasil belajar mandiri mahasiswanya yang berbeda secara signifikan. Dari analisis post hoc uji Mann-Whitney $U$ diperoleh hasil bahwa terdapat perbedaan yang siginifikan kegiatan belajar mandiri dan kegiatan pelaporan hasil belajar mandiri pada kelompok kinerja tutor tinggi dengan sedang $(p=0,000, p=0,000)$, kelompok kinerja tutor tinggi dengan rendah $(\mathrm{p}=0.007, \mathrm{p}=0,008)$, tetapi antara kelompok tutor kinerja sedang dan rendah tidak berbeda signifikan ( $\mathrm{p}=0,111, \mathrm{p}=0,280)$. Dengan kata lain, skor rata-rata kegiatan belajar mandiri dan kegiatan pelaporan hasil belajar mandiri mahasiswa akan semakin baik bila kinerja tutor semakin tinggi.

Tabel 3. Distribusi skor rata-rata kegiatan belajar mandiri dan kegiatan pelaporan hasil belajar mandiri mahasiswa berdasarkan kategori kinerja tutor

\begin{tabular}{|c|c|c|c|c|c|c|}
\hline \multirow{2}{*}{ Variabel } & \multicolumn{3}{|c|}{$\begin{array}{c}\text { Kegiatan } \\
\text { Belajar Mandiri }\end{array}$} & \multicolumn{3}{|c|}{$\begin{array}{c}\text { Kegiatan } \\
\text { Pelaporan Hasil Belajar Mandiri }\end{array}$} \\
\hline & Mean \pm SD & $\begin{array}{c}\text { Skor } \\
\text { Terendah }\end{array}$ & $\begin{array}{c}\text { Skor } \\
\text { Tertinggi }\end{array}$ & Mean \pm SD & $\begin{array}{c}\text { Skor } \\
\text { Terendah }\end{array}$ & $\begin{array}{c}\text { Skor } \\
\text { Tertinggi }\end{array}$ \\
\hline Kinerja Tutor Rendah & $3,12 \pm 0,80$ & 1,43 & 4,07 & $3,08 \pm 0,89$ & 1,25 & 4,12 \\
\hline Kincrja Tutor Scdang & $3,57 \pm 0,41$ & 2,50 & 4,50 & $3,46 \pm 0,44$ & 1,50 & 4,50 \\
\hline $\begin{array}{c}\text { Kincrja Tutor } \\
\text { Tinggi }\end{array}$ & $3,77 \pm 0,43$ & 2,50 & 5 & $3,77 \pm 0,46$ & 2 & 5 \\
\hline $\begin{array}{l}\text { Hasil Uji } \\
\text { Kruskal Wallis }\end{array}$ & \multicolumn{3}{|c|}{$\chi^{2}=23,771 ; \mathrm{p}=0,000^{*}$} & \multicolumn{3}{|c|}{$\chi^{2}=43,320 ; \mathrm{p}=0,000^{*}$} \\
\hline
\end{tabular}

* Signifikan $p<0,05$

\section{PEMBAHASAN}

Tujuan penelitian ini adalah untuk mengetahui pengaruh kinerja tutor terhadap kegiatan belajar mandiri dan pelaporan hasil belajar mandiri dalam PBL, sehingga pembahasan akan difokuskan pada tujuan penelitian ini.
Kinerja Tutor pada Mahasiswa Semester 2 dan Semester 4

Dari hasil penelitian ditemukan bahwa skor rata-rata kinerja tutor pada mahasiswa semester 2 dan semester 4 menunjukkan kinerja yang tinggi. Walaupun terdapat sedikit perbedaan skor rata-rata kinerja tutor pada kedua 
kelompok mahasiswa ini, pengalaman tutor, baik sebagai process expert maupun content expert dalam memfasilitasi tutorial juga perlu diperhatikan. Penelitian yang dilakukan oleh Bochner et al. ${ }^{7}$ membandingkan tutor "expert" dan "non expert", dalam memfasilitasi tutorial menemukan perbedaan yang signifikan pada hasil evaluasi pencapaian keberhasilan belajar mahasiswa pada tutor "content expert", hal ini mungkin disebabkan oleh pengalamannya sebagai tutor akan memahirkan kemampuannya memfasilitasi tutorial. Maudsley ${ }^{8}$ pernah mengutip pendapat yang berbeda dari Schmidt et al tentang peran tutor dalam PBL, bahwa tidak ada pengaruh tutor "content expert" terhadap pencapaian keberhasilan belajar mahasiswa karena tutor yang efektif adalah tutor yang mampu berperan sebagai fasilitator dan juga mampu berperan sebagai pakar yang baik (content expert). Hal yang senada juga pernah dikemukan oleh Mathens et al. ${ }^{9}$ bahwa tidak ada pengaruh tutor "content expert" maupun "process expert" terhadap keberhasilan belajar mahasiswa dalam PBL. Hingga kini masih ada perbedaan pendapat tentang pengaruh tutor "process expert" atau "content expert" dan pengalamannya sebagai tutor serta kualifikasi pendidikan tutor terhadap proses tutorial. Tetapi secara keseluruhan, kinerja tutor memang cukup bervariasi pada kedua kelompok mahasiswa tersebut.

\section{Kegiatan Belajar Mandiri dan Kegiatan Pelaporan Hasil Belajar Mandiri pada Mahasiswa Semester 2 dan Semester 4}

Pada penelitian ini ditemukan bahwa skor rata-rata kegiatan belajar mandiri dan kegiatan pelaporan hasil belajar mandiri pada mahasiswa semester 2 dan mahasiswa semester 4 cukup baik. Hasil penelitian yang berbeda dikemukakan oleh Musal et al. ${ }^{5}$, bahwa skor rata-rata yang merefleksikan kegiatan belajar mandiri mahasiswa lebih baik pada mahasiswa tahun ketiga daripada mahasiswa tahun pertama. Menurut Musal et al., temuan ini disebabkan adanya kesiapan dan perubahan mental pada mahasiswa yang lebih senior dialami sejak awal dan berkelanjutan terus-menerus sebagai bagian adaptasi terhadap proses PBL ini. ${ }^{5}$

Tidak dapat dipungkiri juga adanya perbedaan temuan ini mungkin disebabkan penilaian kegiatan belajar mandiri mahasiswa didasarkan pada persepsi mahasiswa yang sangat dipengaruhi banyak faktor lain, misalnya kelompok mahasiswa dengan antusiasme yang tinggi, rasa percaya diri yang tinggi ataupun motivasi yang baik juga dapat menyebabkan persepsinya menjadi lebih baik terhadap kegiatan belajar mandiri. Penjelasan teoritis lain yang mungkin dapat menerangkan adanya perbedaan dalam temuan ini mungkin disebabkan perbedaan lingkungan belajar yang konstruktivis yang terbentuk dalam proses PBL, dimana kemampuan mahasiswa dalam memotivasi dirinya untuk belajar mandiri, kendali diri untuk belajar yang baik serta kemampuan meminimalkan kecemasan selama mengikuti kegiatan tutorial, juga menjadi faktor yang berperan terhadap kegiatan belajar mandiri mahasiswa yang lebih baik. ${ }^{1}$

\section{Hubungan Kinerja Tutor dengan Kegiatan Belajar Mandiri dan Pelaporan Hasil Belajar Mandiri Mahasiswa}

Pada penelitian ini juga ditemukan bahwa skor rata-rata kegiatan belajar mandiri dan pelaporan hasil belajar mandiri semakin baik, bila kinerja tutor semakin tinggi. Hal ini sejalan dengan yang dinyatakan Schmidt \& Moust, bahwa terdapat hubungan antara kinerja tutor dengan kegiatan belajar mandiri mahasiswa dalam PBL dan mungkin berpengaruh tidak langsung terhadap hasil belajar mahasiswa yang dinilai dari kegiatan pelaporan hasil belajar mandiri mahasiswa dalam PBL. ${ }^{2,10}$ Yalcin et al. ${ }^{11}$ juga menemukan bahwa PBL yang dilaksanakan secara konsisten akan memberi efek yang positif terhadap perkembangan kemampuan belajar mandiri mahasiswa. Hal senada juga diungkapkan oleh Albanese seperti yang disitasi Gwee ${ }^{12}$ tentang berbagai teori (information processing theory, cooperative learning theory, self determination theory, control theory) yang mendasari pelaksanaan PBL dalam proses belajar yang dilakukan oleh seorang pembelajar dewasa.

Bila hasil penelitian ini dikaitkan dengan berbagai tinjauan teori yang ada, maka kegiatan belajar mandiri mahasiswa akan semakin baik, kinerja tutor yang memfasilitasi juga semakin tinggi. Dan apabila kegiatan belajar mandiri mahasiswa semakin baik, maka kegiatan pelaporan hasil belajar mandiri mahasiswa juga akan semakin baik. Walaupun demikian, pengaruh langsung kinerja tutor terhadap kegiatan belajar mandiri maha- 
siswa masih perlu diteliti lebih lanjut, mengingat banyak variabel lain yang belum dapat dikendalikan dalam penelitian ini.

Di sisi lain, perkembangan kemampuan belajar mandiri itu sendiri merupakan suatu bentuk kesiapan mahasiswa untuk belajar sesuai dengan kebutuhannya sendiri sebagai pembelajar dan kesiapan untuk belajar mandiri itu juga dipengaruhi oleh motivasi dan perilaku belajar individu. Mahasiswa yang terpapar PBL terus-menerus dan adanya proses pengulangan yang progresif, seharusnya akan menciptakan seorang pembelajar yang semakin mandiri (independent learner $=$ self directed learner).

\section{KESIMPULAN}

Berdasarkan hasil penelitian dan pembahasan yang telah dilakukan maka dapat ditarik kesimpulan bahwa:

1. Kegiatan belajar mandiri mahasiswa dan pelaporan hasil belajar mandiri mahasiswa akan semakin baik bila kinerja tutor semakin tinggi.

2. Skor rata-rata kinerja tutor pada mahasiswa semester 2 dan semester 4 menunjukkan kinerja yang tinggi.

3. Skor rata-rata kegiatan belajar mandiri dan pelaporan hasil belajar mandiri pada mahasiswa semester 2 dan mahasiswa semester 4 cukup baik.

\section{SARAN}

Dari hasil penelitian yang telah dilakukan maka ada beberapa saran yang dapat disampaikan:

1. Untuk Institusi

Ditemukan adanya hubungan antara aspek kinerja tutor dengan kegiatan belajar mandiri dan kegiatan pelaporan hasil belajar mandiri mahasiswa, maka perlu dilakukan pelatihan tutor dalam PBL yang lebih intensif secara berkesinambungan, sehingga kinerja tutor akan semakin tinggi.

2. Untuk Penelitian Selanjutnya

a. Perlu dilakukan kajian literatur yang lebih luas dan mendalam terhadap kegiatan belajar mandiri dan kegiatan pelaporan hasil belajar mandiri mahasiswa dalam PBL, sehingga diperoleh alat ukur (kuesioner) yang lebih sahih dan andal. b. Perlu dilakukan penelitian lebih lanjut tentang hubungan kinerja tutor dengan kegiatan belajar mandiri dan kegiatan pelaporan hasil belajar mandiri dengan dengan menggunakan metode penelitian kualitatif, instrumen yang lebih sahih dan andal, subjek penelitian yang lebih besar dengan mengendalikan faktor perancu yang mungkin ada.

\section{UCAPAN TERIMA KASIH}

Ucapkan terima kasih disampaikan kepada Bapak Dr. H. Rahmat Nasution, DTM\&H, M.SC, Sp. ParK, selaku Dekan Fakultas Kedokteran Universitas Islam Sumatera Utara, beralamat di Jl. Sisingamangraja No. 2 A Medan, karena atas dukungan, petunjuk dan izin beliau, akhirnya peneliti dapat menyelesaikan dan mempublikasikan hasil penelitian ini.

\section{DAFTAR PUSTAKA}

1. Hendry GD, Frommer M, Walker RA. Constructivism and problem based learning. Journal of Further and Higher Education. 1999;23(3):359-70.

2. Van Berkel HJM, Dolmans DHJM. The influence of tutoring competencies on problems, group functioning and student achievement in problem based learning. Medical Education. 2006;40:730-36.

3. Van den Hurk MM, Wolfhagen IHAP, Dolmans DHJM, Muijtjens AMM, Van der Vleuten CPM. Impact of individiual study on tutorial group discussion. Teaching and Learning in Medicine. 2006; 11(4):196-201.

4. Van den Hurk MM, Wolfhagen IHAP, Dolmans DHJM, Van der Vleuten CPM. Student generated learning issues: a guide for individual study. Education for Health. 1999;12(2):213-21.

5. Musal B, Gursel Y, Taskiran HC, Ozan S, Tuna A. Perceptions of first and third years medical student on self study and reporting process of problem based learning. BMC Medical Education. 2004;4(16).

6. Dolmans DHJM, Ginns P. A short questionnaire to evaluate the effectiveness of tutors in PBL: validity and reliability. Med Teacher. 2005; 27: 534-8.

7. Bochner D, Badovinac RL, Howell TH, Karimbux NY. Tutoring in a problem based curriculum: expert versus non expert. J Dent Educ. 2002;66(11):124651.

8. Maudsley G. Role and responsibilities of the problem based learning tutor in undergraduate medical curriculum. BMJ. 1999;318:657-61. 
9. Matthes J, Marxen B, Linke RM, Antepohl W, Coburger S, Christ H, Lehmacher W, Herziq S. The influences of tutor qualification on the process and outcome of learning in a problem based course of basic medical pharmacology. Naunyn-Schmiedeberg's Arch Pharmacol. 2002;366(1):58-63.

10. Bude L, Imbos T, Wiel MWJVD, Broers NJ, Berger MPF. The effect of directive tutor guidance in problembased learning of statistics on students' perceptions and achievement. Higher Education Journal. 2008;57(1).

11. Yalcin BM, Karahan TF, Karandenizli D, Sahin EM. Short term effects of problem based learning curriculum on student's self directed learning skills development. Croat Med J. 2006;47:491-8.

12. Albanese, M. Problem based Learning: why curricula are likely to show little effect on knowledge and clinical skills. Medical Education. 2000;34:729-38. 